\title{
FAKTOR-FAKTOR YANG MEMENGARUHI AKTIFITAS REMAJA DALAM PERILAKU SEKSUAL DI SMP NEGERI 5 BATANG ANGKOLA KECAMATAN BATANG ANGKOLA KABUPATEN TAPANULI SELATAN TAHUN 2020
}

\author{
Susi Febriani Yusuf', Juliana Lubis ${ }^{2}$ \\ S-1 Ilmu Kesehatan Masyarakat STIKes Darmais Padangsidimpuan ${ }^{12}$ \\ Email : ${ }^{1}$ febrianiyusuf44@gmail.com
}

\begin{abstract}
Sexual behavior in teenagers tends to be increasing. One of the life skills needed to be applied by the teenagers is the skill of how to be assertive. The factors influencing the assertiveness are culture, self-esteem, parents' parenting pattern, peers, knowledge, self-efficacy, and information media. The purpose of this study was to find out the factors influencing the teenagers' assertiveness in sexual behavior at SMP (Junior High School) Negeri5BatangAngkola, BatangAngkolaSubdistrict,Tapanuli Selatan District in 2020. The population of this explanatory study was all of the 363 female students of SMP Negeri5 BatangAngkola and 113 female students from grade VIII and grade IX were selected to be the samples for this study through proportional random sampling technique. The data for this study were directly obtained from the female students through questionnaire distribution. The data obtained were analyzed through multiple logistic regression tests at $\alpha=5 \%$. The result of this study showed that the assertiveness of the female students towards sexual behaviour belonged at the high category (57.5\%), and statistically, culture, self-esteem, peers and self-efficacy had influence on the assertiveness towards the sexual behavior in the teenagers at SMP Negeri5 BatangAngkola. The most dominant influencing variable was peer with the regression coefficient value of 5.011. The management of SMP Negeri5 BatangAngkola should increase assertive behavior of their students by including education in the local curriculum in schools and to cooperate with the students' parents in monitoring tennagers relationship with peers, so that stakeholders teaches teens to be more courageous in making decisions, the respondent must be able to maintain self-esteem.
\end{abstract}

Key Word: Assertiveness, Sexual Behavior,Culture, Self Esteem, Peers

\section{ABSTRAK}

Perilaku seksual pada remaja cenderung meningkat. Salah satu kecakapan hidup yang perlu diterapkan oleh para remaja adalah keterampilan bagaimana bersikap asertif. Faktor-faktor yang mempengaruhi asertif adalah budaya, harga diri, pola asuh orang tua, teman sebaya, pengetahuan, efikasi diri, dan media informasi. Tujuan dari penelitian ini adalah untuk mengetahui faktor-faktor yang mempengaruhi ketegasan remaja dalam perilaku seksual di SMP Negeri 5 BatangAngkola Kecamatan BatangAngkola Kabupaten Tapanuli Selatan Tahun 2020. Populasi penelitian ini adalah seluruh siswi yang berjumlah 363 siswi. SMP Negeri 5 BatangAngkola dan 113 siswi kelas VIII dan kelas IX dipilih menjadi sampel penelitian ini melalui teknik proportional random sampling. Data penelitian ini diperoleh langsung dari mahasiswi melalui penyebaran angket. Data yang diperoleh dianalisis melalui uji regresi logistik berganda pada $=5 \%$. Hasil penelitian menunjukkan bahwa ketegasan mahasiswi terhadap perilaku seksual termasuk dalam kategori tinggi (57,5\%), dan secara statistik budaya, harga diri, teman sebaya dan efikasi diri berpengaruh terhadap ketegasan terhadap perilaku seksual di sekolah. para remaja di SMP Negeri 5 BatangAngkola. Variabel yang paling dominan mempengaruhi adalah teman sebaya dengan nilai koefisien regresi sebesar 5,011. Pihak manajemen SMP Negeri 5 BatangAngkola hendaknya meningkatkan perilaku asertif siswanya dengan memasukkan pendidikan dalam kurikulum lokal di sekolah dan bekerja sama dengan orang tua siswa dalam memantau hubungan dengan teman sebaya, sehingga stakeholder mengajarkan remaja untuk lebih berani dalam mengambil keputusan, responden harus mampu menjaga harga diri.

Kata kunci: Ketegasan, Perilaku Seksual, Budaya, Harga Diri, Teman Sebaya 

Vol. 16 No. 3 September - Desember 2021

\section{PENDAHULUAN}

\section{Latar Belakang (Opsional)}

Salah satu dampak dari Total Fertility Rate (TFR) dan Infant Mortality Rate (IMR) adalah perubahan struktur umur penduduk, diantaranya yaitu terjadinya peningkatan jumlah penduduk usia remaja. Berdasarkan data BPS, 2011, jumlah pemuda Indonesia (penduduk berusia $16-30$ tahun) diperkirakan sebanyak 51,95 juta jiwa atau 25,69\% dari penduduk Indonesia yang berjumlah 241,13 juta jiwa. Dari data tersebut diketahui kelompok umur pemuda yang berusia 16 - 20 tahun sebesar $32,06 \%$. Jumlah remaja yang tidak sedikit ini merupakan potensi yang sangat berarti dalam melanjutkan pembangunan di Indonesia.

Kesehatan Reproduksi Remaja (KRR) dalam Rencana Pembangunan Jangka Menengah Nasional 2004 - 2009, merupakan salah satu dari program pemerintah dalam sektor pembangunan sumber daya manusia.Sasaran dari program ini adalah meningkatkan pengetahuan, sikap dan perubahan prilaku remaja melalui pelayanan dan informasi kesehatan reproduksi (Bappenas, 2007).

Berdasarkan laporan WHO (2012), pada tahun 2008, ada 16 juta kelahiran dari ibu yang berusia 15-19 tahun, yang mewakili 11\% dari seluruh kelahiran yang ada di dunia. Sekitar 95\% dari kelahiran terjadi di negara berpenghasilan rendah dan menengah. Angka kelahiran global remaja ini telah menurun dari 60 per 1000 pada tahun 1990 menjadi 48 per 1000 pada tahun 2007, yang diawali dari 5 per 1000 wanita di Asia Timur menjadi 121 per 1000 di sub-Sahara Afrika pada tahun 2007. The World Bank (2010), juga mencatat laporan dari Millennium Development Goals (MDGs) (2010), dimana tingkat kelahiran remaja usia 15 - 19 tahun adalah 53 per 1000 kelahiran.

Menurut data Riset Kesehatan Dasar (RISKESDAS) tahun 2010 ditemukan dari keseluruhan remaja berumur 10-24 tahun yang berstatus belum menikah adalah $86,7 \%$. Pada kelompok remaja dengan status belum kawin, sebanyak 3,0\% laki-laki dan perempuan 1,1\% mengatakan pernah berhubungan seksual. Lebih lanjut dapat diketahui pula bahwa umur pertama berhubungan seksual sudah terjadi pada usia yang sangat muda, yaitu 8 tahun. Terdapat 0,5 persen perempuan telah melakukan hubungan seksual pertama kali pada usia 8 tahun, dan 0,1 persen pada laki-laki.

Menurut BKKBN (2012), dari 552 remaja yang ada di Sumatera Utara, diketahui sebanyak 86.3\% remaja yang berpegangan tangan ketika berpacaran, $32.2 \%$ remaja yang melakukan cium bibir, dan sebanyak $8.2 \%$ remaja yang melakukan rabaan/rangsangan. Sebanyak $4.9 \%$ laki-laki dan 1.5\% perempuan telah melakukan hubungan seksual pada saat berpacaran.
Berdasarkan survei yang telah dilakukan, diketahui di Kabupaten Langkat 45\% remaja sudah pernah melakukan asusila kepada lawan jenisnya. Pada 9 Puskesmas dari 33 Puskesmas di Kabupaten Langkat, terdapat 181 kehamilan remaja usia 15 - 19 tahun dari 1326 seluruh kehamilan, walaupun dari jumlah dari kehamilan remaja tersebut belum dapat dipastikan akibat dari kehamilan pranikah, namun bisa dipersepsikan bahwa sebagian kehamilan tersebut adalah kehamilan pranikah dari keterangan beberapa bidan koordinator di puskesmas.

Berdasarkan survei yang telah dilakukan di SMP (Sekolah Menengah Pertama) Negeri 5 Sigalangan, diperoleh hasil pada satu kelas yang berisikan 32 siswa terdapat 18 siswa yang mengaku sudah pernah pacaran dan mulai berpacaran pada umur 14 tahun. Tetapi para siswa mengaku gaya berpacarannya masih dalam batas dan rata-rata seperti berpegangan tangan $90 \%$, berciuman bibir $75 \%$. Mereka mengatakan bahwa orang tua mereka mengetahuinya. Ketika ditanya mengenai kehamilan di usia muda, rata-rata dari mereka tidak setuju jika ada remaja seumur mereka sudah hamil, apalagi bila kehamilan tersebut adalah disebabkan perilaku seksual pranikah. Berdasarkan laporan dari guru bimbingan konseling yang ada di SMP tersebut, bahwa belum ada dari siswa mereka yang diberhentikan dari sekolah karena sudah hamil.

Menurut Santrock (2007), remaja merupakan transisi perkembangan antara masa kanak - kanak dan masa dewasa yang meliputi perubahan secara fisik, kognitif dan perubahan sosial. Perkembangan itu dipelajari dan dipengaruhi secara kuat oleh lingkungan.Santrock (2007) juga mengutip pendapat Bandura (2000) menyatakan bahwa perilaku, lingkungan dan personal/kognisi merupakan faktor yang penting dalam perkembangan.

\section{Tujuan Penelitian (Opsional)}

Untuk mengetahui faktor-faktor yang memengaruhi faktor budaya, dan harga diri, pola asuh orang tua, teman sebaya, pengetahuan, self efficacy dan media informasi terhadap asertifitas remaja dalam perilaku seksual di SMP Negeri 5 Batang Angkola Kecamatan Batang Angkola Kabupaten Tapanuli Selatan Tahun 2020.

\section{Hipotesis (Opsional)}

Ada hubungan faktor budaya, dan harga diri, pola asuh orang tua, teman sebaya, pengetahuan, self efficacy dan media informasi terhadap asertifitas remaja dalam perilaku seksual di SMP Negeri 5 Batang Angkola Kecamatan Batang Angkola Kabupaten Tapanuli Selatan Tahun 2020.

\section{METODE}


Penelitian ini merupakan penelitian kuantitatif dengan menggunakan metode survei explanatory reseach. Alasan menggunakan desain ini, karena cocok digunakan pada penelitian untuk mencari pengaruh sebab akibat dari variabel-variabel yang diteliti. Penelitian ini menggunakan pendekatan cross sectional yaitu suatu rancangan penelitian dengan melakukan pengukuran atau pengamatan pada saat bersamaan (sekali waktu) antara faktor risiko/paparan.

Populasi dalam penelitian ini adalah seluruh siswi SMP Negeri 5 Batang Angkola yang berjumlah 363 orang, yang terdiri dari kelas VII sebanyak 113 orang, kelas VIII sebanyak 111 orang dan kelas IX sebanyak 139 orang. keseluruhan sampel pada penelitian ini adalah 113 orang, dengan pengambilan sampel menggunakan proportional random sampling.Untuk mengambil sampel pada masingmasing kelas dilakukan secara proporsional sebanding dengan populasi siswi kelas VIII dan kelas IX..

\section{HASIL}

Berdasarkan karakteristik mayoritas umur responden berada pada rentang umur 13 - 15 tahun yaitu sebanyak 89 orang $(78,8 \%)$, diketahui pula suku mayoritas responden adalah Jawa yaitu sebanyak 62 orang $(54,9 \%)$, dan mayoritas responden memeluk agama Islam yaitu sebanyak 91 orang $(80,5 \%)$ (Tabel 1).

Tabel 1. Faktor-Faktor Yang Memengaruhi Asertifitas Remaja Dalam Perilaku Seksual di SMP Negeri 5 Batang Angkola Kecamatan Batang Angkola Kabupaten Tapanuli Selatan Tahun 2020

\begin{tabular}{|c|c|c|c|c|c|c|c|}
\hline \multirow[t]{3}{*}{ Variabel } & \multicolumn{4}{|c|}{$\begin{array}{c}\text { Asertivitas dalam } \\
\text { Perilaku Seksual }\end{array}$} & \multirow{2}{*}{\multicolumn{2}{|c|}{ Total }} & \multirow{3}{*}{$\begin{array}{l}\mathrm{Ni} \\
\text { lai } \\
\mathrm{P}\end{array}$} \\
\hline & \multicolumn{2}{|c|}{ Tinggi } & \multicolumn{2}{|c|}{ Rendah } & & & \\
\hline & $\mathbf{n}$ & $\%$ & $\mathbf{N}$ & $\%$ & $\mathrm{n}$ & $\%$ & \\
\hline \multicolumn{8}{|l|}{ Budaya } \\
\hline $\begin{array}{l}\text { Menduku } \\
\text { ng }\end{array}$ & 46 & 69,7 & 20 & 30,3 & 66 & 100 & $\begin{array}{c}0.00 \\
2 \\
\end{array}$ \\
\hline $\begin{array}{l}\text { Tidak } \\
\text { Menduku } \\
\text { ng }\end{array}$ & 19 & 40,4 & 28 & 59,6 & 47 & 100 & \\
\hline \multicolumn{8}{|l|}{ Pola Asuh } \\
\hline Otoriter & 11 & 57,9 & 8 & 42,1 & 19 & 100 & $\begin{array}{c}0.27 \\
5 \\
\end{array}$ \\
\hline Permisif & 2 & 28,6 & 5 & 71,4 & 7 & 100 & \\
\hline $\begin{array}{l}\text { Demokrati } \\
\mathrm{s}\end{array}$ & 52 & 59,8 & 35 & 40,2 & 87 & 100 & \\
\hline \multicolumn{8}{|l|}{ Harga Diri } \\
\hline Tinggi & 55 & 65,5 & 29 & 34,5 & 84 & 100 & $\begin{array}{c}8,47 \\
5 \\
\end{array}$ \\
\hline Rendah & 10 & 34,5 & 19 & 65,5 & 29 & 100 & \\
\hline \multicolumn{8}{|l|}{$\begin{array}{l}\text { Teman } \\
\text { Sebaya }\end{array}$} \\
\hline Baik & 50 & 73,5 & 18 & 26,5 & 68 & 100 & $\begin{array}{c}0.00 \\
1 \\
\end{array}$ \\
\hline Buruk & 15 & 33,3 & 30 & 66,7 & 45 & 100 & \\
\hline $\begin{array}{l}\text { Pengetahu } \\
\text { aan }\end{array}$ & & & & & & & \\
\hline
\end{tabular}

\begin{tabular}{|l|c|c|c|c|c|c|c|}
\hline Baik & 47 & 60,3 & 31 & 39,7 & 78 & 100 & $\begin{array}{c}0,77 \\
1\end{array}$ \\
\hline Kurang & 18 & 51,4 & 17 & 48,6 & 35 & 100 & \\
\hline $\begin{array}{l}\text { Self } \\
\text { Efficacy }\end{array}$ & & & & & & & \\
\hline Baik & 49 & 64,5 & 27 & 35,5 & 76 & $\begin{array}{c}10 \\
0\end{array}$ & $\begin{array}{c}0.03 \\
2\end{array}$ \\
\hline Kurang & 16 & 43,2 & 21 & 56,8 & 37 & $\begin{array}{c}10 \\
0\end{array}$ & \\
\hline Media & & & & & & & \\
\hline Banyak & 19 & 65,5 & 10 & 34,5 & 29 & $\begin{array}{c}10 \\
0\end{array}$ & $\begin{array}{c}0.31 \\
2\end{array}$ \\
\hline Sedikit & 46 & 54,8 & 38 & 45,2 & 84 & $\begin{array}{c}10 \\
0\end{array}$ & \\
\hline
\end{tabular}

Berdasarkan hasil analisis multivariat dengan menggunakan uji regresi logistik berganda diperoleh variabel yang paling

berpengaruh atau variabel yang paling dominan adalah teman sebaya dan budaya tabel 2 .

Tabel 2.Hasil Analisis Multivariat Uji Regresi Logistik

\begin{tabular}{|l|c|c|c|c|c|}
\hline $\begin{array}{c}\text { Variabel } \\
\text { Independ } \\
\text { en }\end{array}$ & B & P & $\begin{array}{c}\text { Exp( } \\
\text { B) }\end{array}$ & \multicolumn{2}{|c|}{$95 \%$ CI } \\
\hline & & & & $\begin{array}{c}\text { Lowe } \\
\text { r }\end{array}$ & $\begin{array}{c}\text { Uppe } \\
\text { r }\end{array}$ \\
\hline Budaya & 1,0 & 0,014 & 2,967 & $\begin{array}{c}1,24 \\
5\end{array}$ & 7,067 \\
\hline $\begin{array}{l}\text { Harga } \\
\text { Diri }\end{array}$ & 1,6 & 0,023 & 3,125 & $\begin{array}{c}1,17 \\
1\end{array}$ & 8,339 \\
\hline $\begin{array}{l}\text { Teman } \\
\text { sebaya }\end{array}$ & 1,1 & 0,001 & 5,011 & 2,09 & 11,98 \\
\hline Constant & - & 0,001 & 0,173 & & 8 \\
& 1,75 & & & & \\
\hline
\end{tabular}

\section{PEMBAHASAN}

Menurut Noviasari (2011), asertifitas yang dimiliki remaja membuat dirinya mampu mempertahankan hak-hak seksualnya tanpa merugikan orang lain, sehingga remaja tidak takut dalam menolak pacarnya ketika pacarnya mengajak untuk melakukan hubungan seksual diluar nikah, akibatnya remaja dapat terhindar dari perilaku seksual pranikah. Noviasari (2011) yang mengutip pendapat Imran (2000) juga mengatakan bahwa ada berbagai faktor yang memengaruhi perilaku seksual pranikah salah satunya adalah faktor keterpaksaan, dimana ketika pacar mengajak melakukan hubungan seksual remaja tidak dapat menolaknya.Ketidakmampuan dalam menolak ajakan untuk berhubungan seksual dengan alasan karena takut kehilangan pacarnya.

Marini dkk (2005), mengutip pendapat Hawari dkk (2002), menyatakan bahwa penyebab para remaja terjerumus ke hal yang negatif seperti seks bebas, salah satunya adalah karena kepribadian yang lemah. Ciri - cirinya antara lain daya tahan terhadap 

Vol. 16 No. 3 September - Desember 2021

tegangan dan tekanan rendah, kurang bisa mengekpresikan diri, kurang bisa mengendalikan emosi dan agresivitas serta tidak dapat mengatasi masalah dan konflik dengan baik yang erat kaitannya dengan asertifitas.

Memasukkan asertifitas dalam kurikulum sekolah juga dapat membantu untuk meningkatkan asertifitas remaja dalam perilaku seksual, terutama pada remaja-remaja awal seperti remaja yang bersekolah di SMP Negeri 5 Batang Angkola ini, karena asertifitas akan sangat diperlukan lebih besar pada saat nantinya remaja bertambah usia dan tingkat pendidikan yang lebih tinggi.

Pada analisis univariat didapatkan bahwa responden dengan budaya mendukung sebesar 58,4\% dan sisanya tidak mendukung yaitu $41,6 \%$. Pengaruh budaya terhadap asertifitas dalam perilaku seksual didapat bahwa dari 66 siswi yang berbudaya tinggi terdapat $69,7 \%$ yang memiliki asertivitas dalam perilaku seksual yang tinggi. Hasil uji statistik menunjukkan nilai $p=0,002$ artinya ada pengaruh yang signifikan antara budaya terhadap asertivitas dalam perilaku seksual. Hasil analisis multivariat terdapat pengaruh yang signifikan budaya terhadap asertivitas dalam perilaku seksual dengan nilai $p=$ $0,014<\alpha=0,05)$ dan OR 2,97 dengan 95\% $\mathrm{CI}=1,24$ 7,07 . Kemungkinan responden yang memiliki budaya mendukung memiliki asertifitas dalam perilaku seksual 2,97 kali lebih tinggi dibanding responden dengan yang budayanya tidak mendukung setelah dikontrol dengan variabel harga diri, pola asuh, teman sebaya, selfefficacy, pengetahuan.

Dalam kaitannya dengan perilaku seksual, hasil penelitian yang dilakukan Mulyana dan Purnamasari (2010), menjelaskan sekaligus membuktikan bahwa harga diri menjadi salah satu faktor yang dapat mempengaruhi sikap remaja terhadap perilaku seksual pranikah, dimana hasil analisa korelasi product moment, diperoleh nilai $\mathrm{rxy}=$ 0.328 ( $\mathrm{p}<0.05)$ yang artinya bahwa ada hubungan negatif antara sikap terhadap perilaku seksual pranikah dengan harga diri pada remaja.

Proses pola asuh orangtua meliputi kedekatan orangtua dan remaja, pengawasan orangtua dan komunikasi orangtua dan remaja tentang topik seksualitas, HIV/AIDS dan NAPZA. Dalam hubungan seksual, keterampilan untuk asertifsangat sulit danrumituntuk diperoleh, terutama bagiremaja, namun bagaimanapun saat ini remaja sangat memerlukannya. Di antara proses pola asuh tersebut, komunikasi orangtua dan remaja telah diketahui merupakan pengaruh yang paling penting dan signifikan terhadap sikap dan perilaku remaja tentang kesehatan reproduksi. Hasil penelitian dari Julianti (2011), menunjukkan bahwa dari 170 responden, mayoritas responden $74,1 \%$ (126 orang) dalam kategori pola asuh orangtua authoritative (demokratis) yang berhubungan dengan sikap tentang kesehatan reproduksi.

Emmons (2001) menggolongkan beberapa faktor yang mempengaruhi asertivitas seseorang, keluarga, sekolah, dan tempat kerja. Keluarga sebagai salah satu faktor pendukung asertivitas seseorang memerlukan peran orangtua dalam mendidik anak yang disebut pola asuh.Pola pengasuhan autoritatif (authoritative parenting) atau yang sering disebut pola asuh demokratismerupakan pola asuh yang dianggap paling mendukung peningkatan asetifitas remaja.

Hasil penelitian ini memang menjelaskan bahwa tidak ada pengaruh pola asuh orang tua terhadap asertifitas remaja, hal ini dapat diasumsikan bahwa dalam berperilaku seseorang akan melihat kondisi dan situasi dalam arti luas, salah satunya adalah kedekatan remaja dengan teman sebaya, responden dalam penelitian ini ada kecendrungan lebih dekat dengan teman, dan teman yang dimiliki adalah teman yang dapat mengarahkan kearah yang baik. Hasil tabulasi silang antara pola asuh dan teman sebaya menjelaskan bahwa adanya teman sebaya yang baik mengurangi pengaruh pola asuh orang tua, sehingga walaupun pola asuh orang tua paling tinggi adalah demokratis, tetapi teman sebaya memiliki pengaruh lebih besar terhadap tingginya asertivitas dalam perilaku seksual pada responden.

Hal ini sejalan dengan pernyataan Ristianti (2012) mengutip pendapat Desmita (2005), mengatakan meskipun remaja masih bergantung pada orang tuanya, namun intensitas ketergantungan tersebut telah berkurang dan remaja mulai mendekatkan diri pada teman-teman yang memiliki rentang usia yang sebaya dengan dirinya. Remaja mulai belajar mengekspresikan perasaan-perasaan dengan cara yang lebih matang dan berusaha memperoleh kebebasan emosional dengan cara menggabungkan diri dengan teman sebayanya.

Berdasarkan profil Kecamatan Batang Angkola (2014), mayoritas penduduk Kecamatan Batang Angkola memiliki mata pencaharian sebagai petani yaitu $63 \%$ dari 47.843 penduduk yang ada. Sebagai petani yang bekerja seharian di sawah, cenderung akan sangat sulit memberi perhatian yang optimal kepada anak-anaknya, walaupun secara pengasuhan orang tua tetap memantau perkembangan anak, tetapi banyaknya waktu yang dihabiskan bersama dalam keluarga juga turut mendukung pola kedekatan anak dan orang tuanya.

Pengaruh teman sebaya terhadap asertivitas dalam perilaku seksual didapat bahwa dari 68 orang responden yang memiliki teman sebaya baik terdapat $73,5 \%$ yang asertivitas dalam perilaku seksual tinggi. Terdapat $33,3 \%$ responden yang memiliki teman sebaya yang buruk tetapi memiliki asertivitas dalam perilaku seksual yang tinggi. Hasil uji statistik menunjukkan nilai $p=0,001$ artinya ada pengaruh 
yang signifikan antara teman sebaya terhadap asertivitas dalam perilaku seksual.

Ristianti (2010) mengutip pendapat Cairns \& Neckerman (1988) menyatakan bahwa keberadaan teman sebaya dalam kehidupan remaja merupakan keharusan, untuk itu seorang remaja harus mendapatkan penerimaan yang baik untuk memperoleh dukungan dari kelompok teman sebayanya. Melalui berkumpul dengan teman sebaya yang memiliki kesamaan dalam berbagai hal tertentu, remaja dapat mengubah kebiasan-kebiasan hidupnya dan dapat mencoba berbagai hal yang baru serta saling mendukung satu sama lain. Hal senada juga dikutip Ristianti (2010) dari Tarakanita (2001) yang mengatakan bahwa, teman sebaya selain merupakan sumber referensi bagi remaja mengenai berbagai macam hal, juga dapat memberikan kesempatan bagi remaja untuk mengambil peran dan tanggung jawab yang baru melalui pemberian dorongan (dukungan sosial).

Pertemuan remaja dengan teman sebaya dapat dilakukan baik di sekolah melalui kegiatan-kegiatan seperti OSIS (Organisasi Intra Sekolah), dan UKS (Usaha Kesehatan Sekolah) yang terdapat di lingkungan sekolah SMP Negeri 5 Batang Angkola, dan dapat juga di lingkungan masyarakat seperti perkumpulan remaja mesjid, karang taruna, dll, yang semua kegiatan tersebut berjalan baik di lingkungan Kecamatan Batang Angkola. Dengan banyaknya aktifitas-aktifitas yang positif tersebut dapat membantu remaja dalam memperoleh teman yang mendukung dalam perilaku yang baik.

Menurut Notoatmodjo (2007), secara garis besar, ada dua tekanan pokok yang berhubungan dengan kehidupan remaja, yaitu internal pressure dan external pressure. Dalam hal ini, internal pressure yaitu tekanan dari dalam diri remaja berupa tekanan psikologis dan emosional, sedangkan external pressure yaitu tekanan dari luar diri remaja seperti teman sebaya, orang tua, guru dan masyarakat.

Namun, walaupun pada saat ini pengaruh teman sebaya masih kategori baik terhadap pembentukan asertifitas remaja, tidak menutup kemungkinan pengaruh tersebut berubah kearah yang tidak baik, sehingga tetap diperlukan pengawasan orang tua dalam memantau hubungan anak remaja dengan teman sebaya.

Pengaruh pengetahuan dengan asertifitas dalam perilaku seksual didapat bahwa dari 78 responden berpengetahuan baik terdapat $60,3 \%$ yang asertifitas dalam perilaku seksual tinggi. Terdapat $51,4 \%$ responden yang berpengetahuan kurang tetapi memiliki asertivitas dalam perilaku seksual tinggi. Hasil uji statistik menunjukkan nilai $p=0,380$ artinya tidak ada pengaruh yang signifikan antara pengetahuan terhadap asertifitas dalam perilaku seksual. Walaupun nilai $p>0,25$, pengetahuan tetap dimasukkan kedalam model analisis multivariat, dikarenakan secara teori memengaruhi perilaku, namun hasil analisis tidak menunjukkan pengetahuan memengaruhi asertifitas remaja dalam perilaku seksual $(p>0,05)$.

Pengaruh self-efficacy dengan asertivitas dalam perilaku seksual didapat bahwa dari 76 responden dengan self-efficacy baik terdapat $64,5 \%$ yang asertivitas dalam perilaku seksual tinggi. Terdapat 43,2\% responden dengan self-efficacy kurang tetapi memiliki asertivitas dalam perilaku seksual tinggi. Hasil uji statistik menunjukkan nilai $p=0,032$ artinya ada pengaruh yang signifikan antara selfefficacy terhadap asertivitas dalam perilaku seksual.

Dalam situasi yang sama tidak semua individu memberikan respon yang sama. Hal ini dipengaruhi oleh tipe kepribadian seseorang. Dengan tipe kepribadian tertentu seseorang akan bertingkah laku berbeda dengan individu dengan tipe kepribadian lain. Harga diri dapat menumbuhkan keyakinan seseorang yang turut memengaruhi kemampuan untuk melakukan penyesuaian diri dengan lingkungan, sementara itu Self efficacy persepsi seseorang terhadap kompetensi mereka yang juga diperlukan dalam menghadapi lingkungan, hal inilah yang menyebabkan walaupun self-efficacy tinggi, tetap tidak kuat memengaruhi asertivitas dalam perilaku seksual dikarenakan adanya harga diri yang tinggi.

\section{KESIMPULAN}

Berdasarkan hasil penelitian yang didapatkan bahwa faktor yang sangat berpengaruh pada asertifitas remaja dalam perilaku seksual yaitu pengaruh teman sebaya dan pengaruh budaya, sehingga tetap dibutuhkan pengawasan dari orangtua dalam memantau hubungan anak remaja dengan teman sebaya.

\section{DAFTAR PUSTAKA}

1. Hapsari, R., M. (2010). Sumbangan perilaku asertif terhadap harga diri pada karyawan. Artikel; $\quad$ Fakultas Psikologi,Universitas Gunadarma.

2. Hardjana, A. M. (2001). Training SDM yang efektif. Yogyakarta: Kanisius.

3. Hidayah, I. P. (2011). Pengaruh Asertivitas Terhadap Perilaku Seksual Pranikah Pada Remaja Perempuan. Skripsi (tidak diterbitkan). Fakultas Psikologi Universitas Sumatera Utara.

4. Lioni, A., \& Pratiwi, T. (2013). Penerapan Assertive Training Untuk Mengurangi Perilaku Negatif Berpacaran Pada Siswa Kelas X-1 SMA Negeri 1 Porong. Jurnal BK. UNESA 4 (1); 2831.

5. Winarsunu, T. (2002). Statistik: dalam penelitian psikologi dan pendidikan. Malang: UMM Press.

6. Wahyuningsih, D. (2009). Pengaruh Assertiveness Training Terhadap Perilaku Kekerasa Pada Klien Skizofrenia. Jurnal Keperawatan Indonesia. 14 (1): 1- 114. 